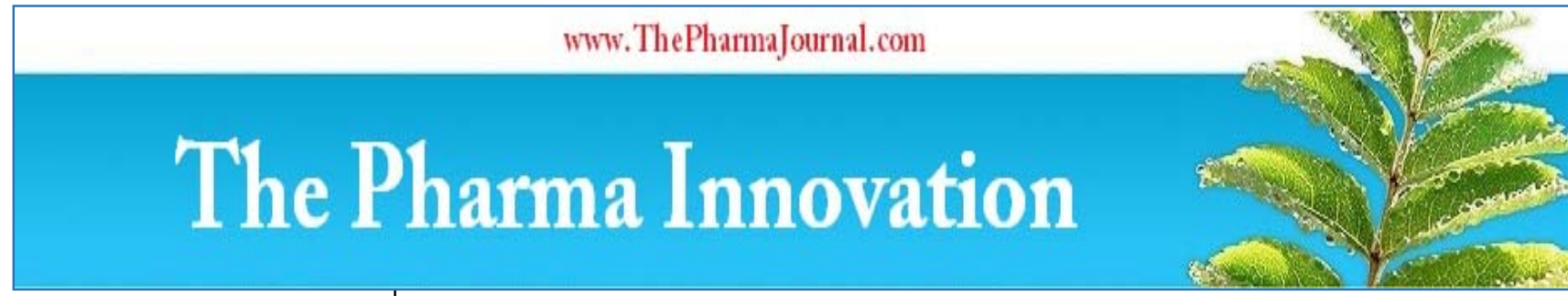

ISSN (E): 2277 - 7695

ISSN (P): 2349-8242

NAAS Rating: $\mathbf{5 . 0 3}$

TPI 2020; 9(2): 162-168

(C) 2020 TPI

www.thepharmajournal.com

Received: 17-12-2019

Accepted: 21-01-2020

Skarma Choton

Division of Food Science and

Technology, SKUAST-J,

Chatha, Punjab, India

Neeraj Gupta

Division of Food Science and

Technology, SKUAST-J,

Chatha, Punjab, India

Julie D Bandral

Division of Food Science and

Technology, SKUAST-J,

Chatha, Punjab, India

Nadira Anjum

Division of Food Science and

Technology, SKUAST-J,

Chatha, Punjab, India

Ankita Choudary

Division of Food Science and

Technology, SKUAST-J,

Chatha, Punjab, India

Corresponding Author:

Skarma Choton

Division of Food Science and

Technology, SKUAST-J,

Chatha, Punjab, India

\section{Extrusion technology and its application in food processing: A review}

\author{
Skarma Choton, Neeraj Gupta, Julie D Bandral, Nadira Anjum and \\ Ankita Choudary
}

DOI: https://doi.org/10.22271/tpi.2020.v9.i2d.4367

\begin{abstract}
Extrusion technology is gaining increasing popularity in the global agro-food processing industry, which employs mixing, forming, texturing and cooking to develop a novel food product. Extrusion cooking is a high-temperature short-time (HTST) process which inactivates enzymes and reduces microbial contamination. Extrusion cooking is mostly preferred, as it has high productivity and significant nutrient retention as compared to conventional cooking. The extrusion technology has become an important technique in food processing industries with its numerous advantages over other processing methods. It is one of the cost effective method and offers a platform for processing of different products from various food groups by modifying minor or major ingredients and processing conditions. Extrusion technology is applied in food processing industry for the development of variety of snacks, pasta, breakfast cereals, pet foods, supplementary foods and other textured foods. It is an economical technology for incorporating food processing by-products and residue back into the food stream. The versatility of extrusion technology makes it convenient for development of nutritionally rich fortified products and value added products with combination of different inexpensive raw materials. Extruded products have less moisture content, longer shelf life and are microbiologically safe. The variability of the product and high quality, productivity of the new foods and minimal processing time are the advantages of this technology.
\end{abstract}

Keywords: Extrusion, extruded product, supplementary foods, textured foods, versatility

\section{Introduction}

As generation changes, changing in lifestyle and limited free time has brought a lot of behavioral changes toward foods. Now a day's consumers do choice for convenient ready to eat and ready to cook food with nutritionally rich and therapeutic benefits. Thus to fulfill the demand of consumer, extrusion technology is used. Extrusion technology has become an important technique in food processing industries as it one of the cost effective method. Extrusion processing is defined as the process by which moistened, starchy and proteinaceous food materials are plasticized through a die by a combination of moisture, pressure, heat and mechanical shear (Maurya and Said, 2014) ${ }^{[21]}$. The extrusion process is an effective continuous process in which few unit operations like mixing, shearing, heating, pumping, forming, and sizing combines uniquely to from the products (Agarwal and Chauhan, 2019) ${ }^{[1]}$. Food extrusion is a form of extrusion used in food processing in which a set of mixed raw ingredients are forced through an opening or die with a design specific to the food, and is then cut to a specified size by blades. The machine which forces the mix through the die is an extruder, and the mix is known as the extrudate. The extruder consists of a large, rotating screw tightly fitting within a stationary barrel, at the end of which is the die through which desirable expanded product is formed. Processing of food at high temperature remains a challenge in food processing industries as it leads to deterioration of nutritive values in food due to high temperature. In order to avoid this, extrusion cooking is preferred, as it owes high productivity, significant nutrient retention and minimal processing time as compared to conventional cooking. Extrusion cooking is a high-temperature short-time (HTST) process which inactivates enzymes and reduces microbial contamination in food (Borodoli and Ganguly, 2014) ${ }^{[8]}$.

Extrusion brings gelatinization of starch, denaturation of proteins, reduces lipid oxidation and anti-nutritional factors. In addition, it is considered a versatile, low cost and very efficient technology in the food processing (Pansawat et al., 2008) ${ }^{[23]}$, to produced wide range of 
nutritionally rich value added product. It is one of the contemporary food processing technologies applied for development of variety of snacks, textured and supplementary foods. Extruded products have less moisture content, longer shelf life, nutritionally rich and are microbiologically safe (Pathak and Kochhar, 2018) ${ }^{[24]}$.

\section{History}

Extruders were developed in the 1870s for the production of sausage. Single-screw extruder was evolved during the 1930s and was used to mix semolina flour and water to make pasta products. It was also used in the process of making ready-toeat (RTE) cereals to shape hot, precooked dough. In both of these applications, the level of shear rate was low. During the late 1930s and 1940s, directly expanded corn curls were produce using extruders, which were characterized by extremely high shear rates. The first patent on an application of twin-screw extrusion technology was filed in the mid1950s. Since then the application of extrusion technology in food processing has advanced, widened and grown dramatically (Rao and thejaswini, 2015) ${ }^{[26]}$.

\section{Principle of extrusion process}

The principles of operation in extrusion include raw materials are fed into the extruder barrel and the screw(s) then convey the food along it. Further down the barrel, smaller flights restrict the volume and increase the resistance to movement of the food. As a result, it fills the barrel and the spaces between the screw flights and becomes compressed. As it moves further along the barrel, the screw kneads the material into a semi-solid, plasticized mass. If the food is heated above 100 ${ }^{\circ} \mathrm{C}$ the process is known as extrusion cooking (or hot extrusion). Here, frictional heat and any additional heating that is used cause the temperature to rise rapidly. The food is then passed to the section of the barrel where pressure and shearing is further increased due to smaller flight. Finally, it is forced through one or more restricted openings (dies) at the discharge end of the barrel as the food emerges under pressure from the die, it expands to the final shape and cools rapidly as moisture is flashed off as steam. A variety of shapes, including tubes, rods, spheres, strips, doughnuts, squirls or shells can be formed. Typical products include a wide variety of low density, expanded snack foods and ready-to-eat (RTE) puffed cereals. Cold extrusion, in which food temperature remains at ambient is used to mix and shape foods such as pasta and meat products. Low pressure extrusion, at temperatures below $100^{\circ} \mathrm{C}$, is used to produce, for example fish pastes, surimi, liquorice and pet foods (Bordoloi and Ganguly, 2014) ${ }^{[8]}$.

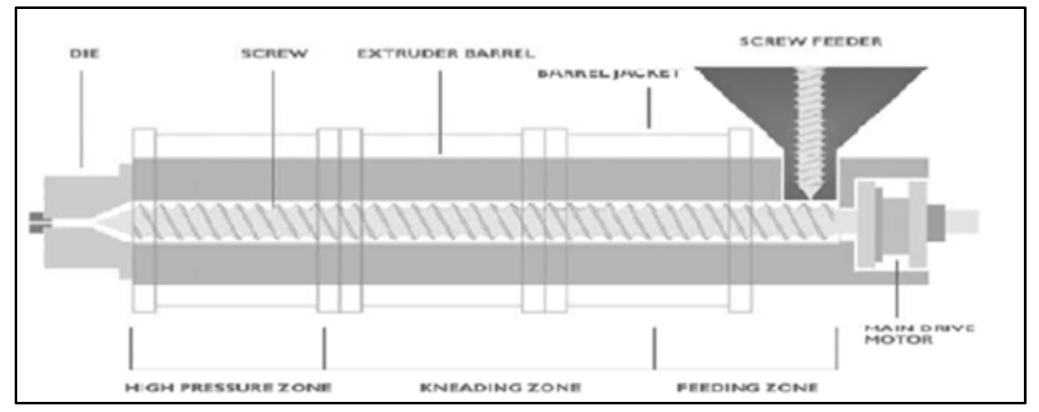

Fig: Schematic representation Of an extruder including its main parts and zones.

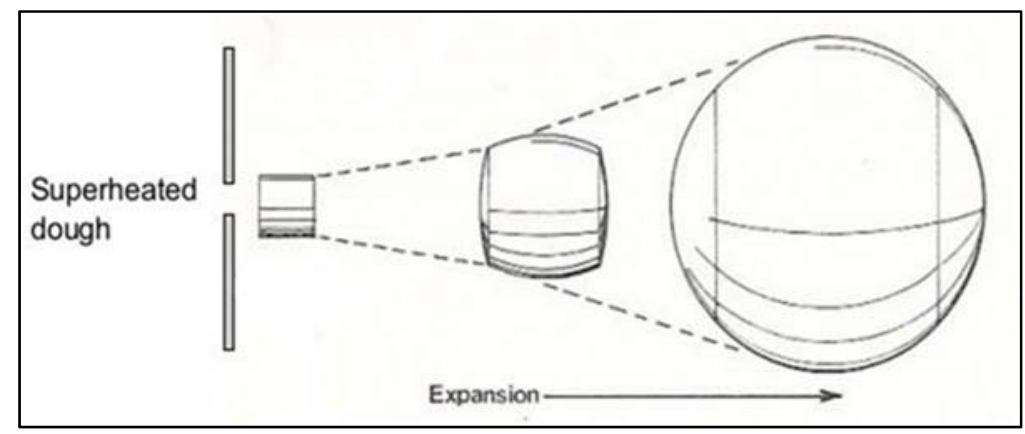

Fig 2: Expansion of dough at die exit

\section{Extruder and its classification}

Extruder is equipment which is used for extrusion processing. Food extruders may be designed to perform several unit operations concurrently, including mixing or homogenization, shearing, starch gelatinization, protein denaturation, texturization, enzyme inactivation, thermal cooking, pasteurization, dehydration, shaping and size reduction (Akhtar et al., 2015) ${ }^{[2]}$. Extruders are composed of five main parts: (i) the pre-conditioning system; (ii) the feeding system; (iii) the screw or worm; (iv) the barrel; (v) the die and the cutting mechanism. They can vary with respect to screw, barrel and die configuration. The selection of each of these items will depend on the raw material used and the final product desired (Riaz, 2000) ${ }^{[27]}$.

(i) Pre-conditioning: Pre-conditioning is done with steam or water and mixed manually. This is applied when moisture contents around 20 to $30 \%$ and long residence times of the material are used. Preconditioning favours uniform particle hydration, reduces retention times within the extruder and increases throughput, due to a reduction in the wearing of barrel and screw components increase the life of the equipment and reduce the costs of energy involved in the process. 
(ii)Feeding system: Feeding of raw material into extruder should be constant and non-interrupted for an efficient and uniform functioning of the extrusion process.

(iii) Screw: Screw convey material into the extruder barrel, shearing and ensure final product quality.

(iv) Barrel or sleeves: It is divided into feeding, kneading and sleeves they are often jacketed to permit circulating of steam or superheated oil for heating or water or air for cooling, thus enabling the precise adjustment of the temperature in the various zones of the extruder (v) Die and Cutting mechanism: The die presents two main functions: give shape to the final product and promote resistance to material flow within the extruder causing an increase in internal pressure. The die can present in various designs and number of orifices. The cutting mechanism must permit obtaining final products with uniform size. Product size is determined by the rotation speed of the cutting blades. This mechanism can be horizontal or vertical (Rao and Thejaswini, 2015) ${ }^{[26]}$.

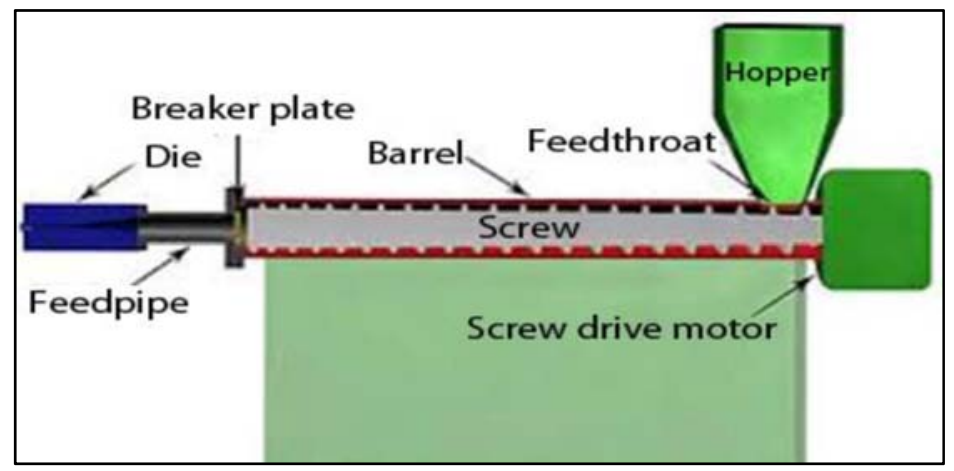

Fig 3: Different parts of extruder

\section{Extruders are categorized on the basis of}

(i) Method of operation

- Cold Extruders and

- Hot Extruders (Extrusion Cooking)

(ii) Method of construction

- Single-screw extruder

- Twin screw extruder

Hot extrusion: generally consist of thermo-mechanically transform raw materials in short time and high temperature (HTST) conditions under pressure. It is used mainly to produce textured food and feed products, such as ready-to-eat breakfast cereals, snacks etc.
Cold extrusion: is used to gently mix and shape dough, without direct heating or cooking within the extruder. In food processing, it is used mainly for producing pasta.

\section{Single screw extruder}

Single screw extruders contain a single rotating screw in a metal barrel. The most commonly used single scews have a constant pitch and come in varying patterns. The raw materials are fed from the hopper located in the feed section and the rotating screw conveys the material to the transition section. In the transition section, the screw channel becomes shallower and the material is compacted results in a rise in temperature of the material. Starch becomes gelatinized, and the material becomes more cohesive. It is transported further by the metering section and pushed through the die opening (Rao and thejaswini, 2015) ${ }^{[26]}$.

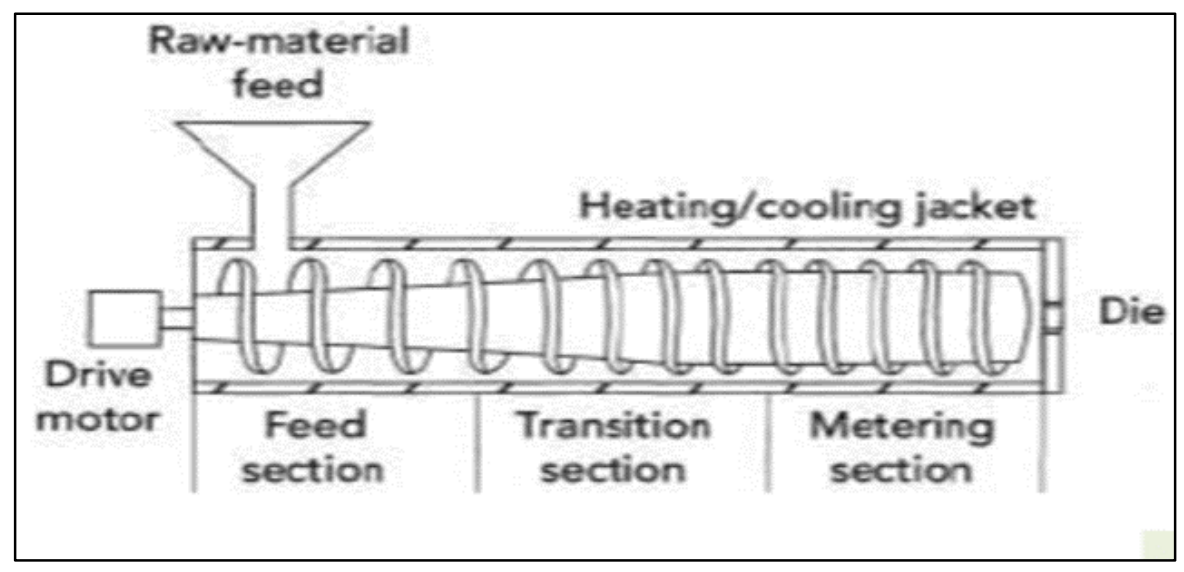

Fig 4: Single screw extruder

\section{Twin-Screw Extruders}

It consists of two parallel screws of equal length rotate inside the same barrel, usually the internal surface of the barrel of twin screw extruders is smooth. It is more complicated than single screw extruders, provides much more flexibility and better control. Twin-screw extruders are used for high moisture extrusion, products that include higher quantities of components such as fibres, fats, etc. and more sophisticated 
products. Depending on the position of the screws and their direction of rotation, four different types of configurations are possible: (i) co-rotating intermeshing screws; (ii) co-rotating non-intermeshing screws; (iii) counter-rotating intermeshing screws (iv) counter-rotating non-intermeshing screws (Maurya and Said, 2014) ${ }^{[21]}$.

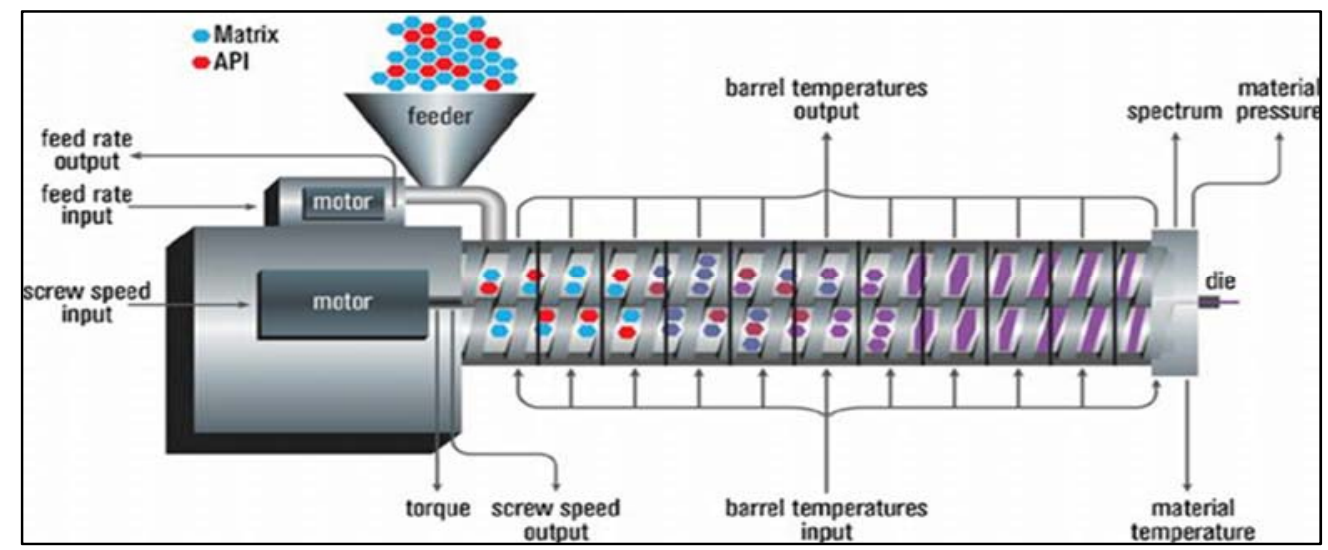

Fig 5: Twin screw extruder

\section{Raw material or Ingredients used in Extrusion:}

Extrusion cooking processes cover various combinations of ingredients including: cereals, grains and starches, tubers, oil seeds, legumes, cereals as well as meat and proteins (Ilo et al, 2000) ${ }^{[16]}$. The main characteristics of the raw material for extrusion cooking are type of material, physical state moisture content, $\mathrm{pH}$ and chemical composition (quantity and type of starch, proteins, fats and sugars) of the material. Most raw materials used in food extrusion are solid (Steel et al., 2012) [32]. Most products, such as snacks, breakfast cereals and biscuits are formed from starch, while protein is used to produce products that have meat-like characteristics and that are used either as full or partial replacements for meat in ready meals, dried foods and many pet food products (Guy, 2001) ${ }^{[15]}$.

\section{Effects of extrusion on physio-chemical properties (i) Changes in physical parameters}

The changes in colour of product could be due to the nonenzymatic browning by Millard reaction between proteins and reducing sugars that occurs due to the high temperature (Petitot et al., 2009) ${ }^{[25]}$. The process conditions used in extrusion cooking high barrel temperatures and low feed moistures favours the Millard reaction and also decreases the nutritional availability of lysine (Camire, 2000) ${ }^{[9]}$. Increasing protein content at constant feed moisture content causes an increase in brittleness, hardness and crispness but decrease colour intensity.

(ii) Changes in composition: Extrusion results in changes in the chemical components of food. The changes are described below.

\section{Dietary fiber}

Fruit and vegetables contain large amounts of dietary fibre (DF), which benefits the physiological activities of humans by decreasing cholesterol levels, reducing hyperlipidemia and hypertension, and maintaining gastrointestinal health (Kendall et al., 2010) ${ }^{[18]}$. Moreover, DF in vegetables and fruits has a higher insoluble/ soluble dietary fibre (IDF/SDF) ratio. In particular, SDF is more effective than IDF in maintaining systemic health. An extrusion technology was successfully applied to orange pomace to increase its SDF fraction under optimal conditions. The increase in SDF content in the extrusion was mainly contributed by redistribution of IDF to SDF, which was likely due to modification of the cell-wall structure during extrusion, where degradation of IDF generally occurs (Huang and Ma, 2015).

\section{Protein}

The change in the screw-speed during extrusion leads to the variation in shear forces which play an important role in changing the nutritional value of proteinaceous materials. Researchers found behavior of molecular aggregation and chemical cross-linking of soybean protein at both low and high moisture content during extrusion. The results showed that, hydrophobic interactions, hydrogen bonds, disulfide bonds, and their interactions collectively hold the structure of protein extrudate regardless of the location and moisture level in the extruder and the contribution of non-covalent bonds during process also exceeds covalent bonds to bring about the change (Chen et al, 2011) ${ }^{[10]}$. Denaturation of proteins at high temperature during extrusion cooking inactivates antinutritional factors (such as antitrypsin factor, lectins, etc.) and improves digestibility. The extrusion of soy protein reduces the undesirable volatile compounds and the bitter taste (Maurya and Said, 2014) [21]. Very high drying temperatures have shown to decrease in protein digestibility and lysine bioavailability (Singh et al., 2007) ${ }^{[31]}$.

\section{Carbohydrate}

During extrusion process, starch undergoes various structural changes including gelatinization, melting, and fragmentation and the extent of the transformation depends upon pressure, temperature, moisture content, and shearing force. Control of sugars during extrusion is critical for nutritional and sensory quality of the products. It is reported that sugar losses in extrusion and it may be explained based on the conversion of sucrose into glucose and fructose (reducing sugars) and loss of these reducing sugars during Maillard reactions with proteins (Navale et al., 2015). The destruction of these flatulence-causing oligosaccharides might improve the nutritional quality of extruded legume products (Singh et al., 2007) ${ }^{[31]}$.

\section{Lipids}

The changes in physicochemical properties of lipids during extrusion are complex and vary with the hydrophilic- 
lipophilic balance of lipids, amount, type and the materials being extruded. These are due to the binding of lipid with starch. High temperature decreases the factors that favours free fatty acid development and oxidation of fatty acids because of the reduction in lipase and lipoxygenase activity (Agarwal and Chauhan, 2019) ${ }^{[1]}$.

\section{Minerals and vitamins}

Extrusion cooking have significant effect on the stability of vitamins in extruded snack food for example low feed moistures and higher barrel temperatures can lead to loss of ascorbic acid. They observed that extrudates obtained from short barrel $(90 \mathrm{~mm})$ extruders had a higher retention rate of B vitamin group (44-62\%) compared to $20 \%$ for long barrel extruders (Athar et al, 2006) ${ }^{[6]}$. The stability of fat soluble vitamins such as vitamin $\mathrm{A}$ and $\mathrm{E}$ are also impacted by the high temperature, short-time extrusion cooking (Tiwari and Cummins, 2009) ${ }^{[33] .}$

\section{Antinutrients}

Nutritional quality of legumes - cereals mixtures could be limited by the presence of antinutrients such as phytic acid, tannic acid, trypsin inhibitors, which inhibit protein digestibility. Extrusion process caused a significant reduction in phytic acid content ranged from $40.64 \%$ to $46.07 \%$ and tannic acid content ranged from $40.46 \%$ to $44.88 \%$ of the germinated dehulled chickpea incorporated corn blends (Hamada et al., 2017).

\section{Antioxidant and total phenol content}

The antioxidants are substances that prevent the oxidation of the molecule especially, fat and fat containing foods. The antioxidant activity of most foods is mainly caused by phenolic compounds. extrusion process caused a significant increase in total phenolic content and antioxidant of the extrudates by $1.92-7.94 \%$ and $1.07-5.55 \%$, respectively (Hamada et al., 2017). This may be attributed to the increased release of the bioactive compounds from the cell wall matrix due to extrusion process thus accessible in the extraction (Zielinski et al., 2006) ${ }^{[35]}$.

\section{Advantages of extrusion technology}

- Versatility - a wide range of products by changing the ingredients, extruder operating conditions and dies.

- Cost - extrusion has lower processing costs and higher productivity than other cooking and forming processes.

- Productivity - extrusion is a continuous process with high output.

- Product Quality - extrusion cooking involves high temperature short time (HTST), retaining many heat sensitive components of a food and minimizes nutrient and flavor losses (Fellow, 2000).

- Environment friendly - as a low-moisture process, extrusion cooking does not produce significant process effluents.

- Energy efficient- extrusion processing operate at relatively low moistures while cooking food products. Lower moisture reduces the quantity of heat required for cooking and redrying the product after cooking (Harper, 1981).

- Production of new foods - Extruders can modify starches, proteins, and other food materials to produce a wide variety of new food products.

\section{Disadvantages of extrusion technology}

- Fading of product color due to expansion on excessive heat.

- Due to the elevated temperatures and low moisture conditions used, different chemical reactions such as the non-enzymatic browning and caramelization can take place.

- Temperature treatment of food material containing proteins and reducing sugars usually leads to a deterioration of the nutritional characteristic of proteins (lysine).

\section{Application of Extrusion technology}

Extrusion technology is applied in food processing industry for the production of human consumption extruded foods, pet foods and value addition of food wastes and by products. Extrusion presents an economical technology for incorporating food processing by-products and residues back into the food stream.

(i) Human consumption products: It is used in production of wide range of products, such as snacks, breakfast cereals, meat and cheese analogues, supplement foods, infant foods and other textured foods (Hamada et al., 2016).

\section{Confectionary products}

Extrusion cooking (HTST) is used to produce a chewy, gelatinized product such as fruit gums and liquorice, from a mixture of sugar, glucose and starch. The heat gelatinises the starch, dissolves the sugar and vaporises excess water which is vented from the machine. Colourings and flavours are added to the plasticised material and, after mixing, it is cooled and extruded. The product texture can be adjusted from soft to elastic by control over the formulation and processing conditions, the shape can be changed by changing the die, and a variety of flavours and colours may be added (Fellows, 2000) ${ }^{[13]}$. These different combinations permit a very large range of potential products, including liquorice, boiled sweets, creams, toffee, fudge and chocolate, each produced by the same equipment.

\section{Breakfast cereals}

Breakfast cereals are available in two types: ready-to-eat cold and hot cereals (traditional cereals). In order to reduce inhome preparation time, breakfast cereal technologies have advanced from grain milling procedures for hot cereals requiring some cooking, to more sophisticated processing methods for manufacturing RTE extruded products, that are highly convenient. The RTE cereals are usually cooked and modified by flaking, toasting, puffing, shredding or extruding (Varsha and Pavani, 2016) ${ }^{[34]}$.

\section{Meat analogues}

A meat analog, also called a meat substitute, mock meat, faux meat or imitation meat, approximates certain aesthetic qualities and chemical characteristics of specific types of meat. Meat analogue, also called a meat substitute, mock meat, faux meat, or imitation meat (Sadler, 2004). Meat analogues are made from soy protein or gluten (Joshi and Kumar, 2015), (Table1) common forms of meat analogue and (Table 2) sources of meat analogue 
Table 1: Common forms of meat analogues

\begin{tabular}{|c|c|c|}
\hline Coarse ground-meat analogues & Emulsified meat analogues & Loose fill \\
\hline Burgers & Deli 'meats' & Taco fillings \\
\hline Sausages & Frankfurters & Chili mixes \\
\hline Batter/breaded nuggets & Spreads & Sloppy Joe \\
\hline Meat' balls & & \\
\hline Pizza toppings & & \\
\hline
\end{tabular}

Table 2: Major nonmeat protein sources suitable for meat analogue

\begin{tabular}{|c|c|c|}
\hline Type of protein & Sources & References \\
\hline b-conglycinin & Soybean & Sun et al. (2008) \\
\hline $\begin{array}{c}\text { Glycinin, } \\
\text { Vicilin }\end{array}$ & Legumes & Kang et al. (2007) \\
\hline Legumin, Albumins, Globulins Glutelins & Oil seeds & Marcone (1999) \\
\hline Gluten Gliadins Glutenins & Wheat, rye, and barley & Green and Cellier (2007) \\
\hline Mycoprotein & Fusarium venenatum (Filamentous fungus) & Denny et al. (2008) \\
\hline
\end{tabular}

Textured vegetable proteins (TVP) are generally, those fabricated vegetable products that can be used to replace meat completely in a food serving. TVP is produced using hot extrusion of defatted soya proteins, resulting in expanded high protein chunks, nuggets, strips, grains and other shapes, where the denatured proteins give TVP textures similar to the meat. The fibrous, insoluble, porous TVP can soak up water or other liquids a multiple of its own weight. Textured soy proteins (TSP) are processed to impart a structure and appearance that resembles meat, seafood or poultry when hydrated. Soy protein products have become increasingly popular because of their low price, high nutritional quality, and versatile functional properties.

(ii) Value addition to food wastes and by-products

Food processing wastes encompass all food residues left behind from various processing operations (Shilev et al., 2006). Processing residues include those generated from processed fruits and vegetables, dairy and meat products, grain mill and bakery products, sugar and confectionary products, fat and oil processing, beverages and other sundry food preparation residues. These by-products are valuable sources of antioxidants, essential fatty acids, dietary fiber, minerals, vitamins, and phytochemicals including polyphenols, carotenoids, phytosterols, and hesperidin (Varzakas et al., 2016). With the numerous advantages of extrusion cooking in handling diverse food materials at low cost, several of these industrial by-products and residues have found useful application in extruded products. A diverse range of extruded foods have been developed using byproducts from food industries, and these materials naturally influence the textural, functional, sensorial, physical and nutritional characteristics of the products (Altan and Maskan, 2016) ${ }^{[5]}$. Extrusion processing is a useful tool for handling diverse raw materials and provides a useful means by which unconventional, under-utilized nutrient sources and food processing residues can be incorporated into food systems. Under-utilized cereals, pseudo cereals and food materials which have demonstrated low economic or processing value have been successfully integrated into consumer markets. Some fruit and vegetable residues and by-products which have been used to develop extruded foods include tomato peel and seed (Devi et al., 2016) ${ }^{[11]}$, pineapple waste pulp (Kothakota et al., 2013) ${ }^{[19]}$, carrot pomace (Alam and Kumar, 2014; Kumar et al., 2010) ${ }^{[3]}$.
(iii)Pet foods and animal feeds:

Extrusion is also used to prepare semi-moist and dry expanded pet foods, aquatic food, and foods for laboratory animals. Whereas, cat and dogs foods are directly extruded and dried. Feed for ornamental fish, high-grade complete feeds to maintaining the health, foods for exotic species in aquariums can also be made from extrusion process (Rao and Thejaswini, 2015) ${ }^{[26]}$. This permits better utilization of available cereal grains, vegetable and animal proteins.

\section{Conclusion}

Extrusion processing provides a great versatility for the development of low cost, high nutritive and convenience food products. The extruded products have the potential of replacing conventional snack foods that are low nutrients. Extrusion process improved the nutritional value and reduced antinutrients i.e. phytic acid and tannic acid of the products as well as improving their protein digestibility and antioxidant activity. This technology because of its beneficial effects such as destruction of antinutritional factors, increased soluble dietary fibres, reduction of lipid oxidation and contaminating microorganisms plays an important role in the production of a wide variety of foods and ingredients.

\section{References}

1. Agarwal S, Chauhan ES, Extrusion processing: The effect on nutrients and based products. The Pharma Innovation Journal. 2019; 8(4):464-470

2. Akhtar J, Malik S, Alam MA, Student MT, Allahabad S. Extrusion technology used for novel Foods Production. International Journal of Engineering Development and Research. 2015; 3:1-7.

3. Alam S, Kumar S. Optimization of extrusion process parameters for red lentil-carrot pomace incorporated ready-to-eat expanded product using response surface. Food Science and Technology. 2014; 2:106-119.

4. Alam MS, Pathania S, Sharma A. Optimization of the extrusion process for development of high fibre soybeanrice ready-to-eat snacks using carrot pomace and cauliflower trimmings. LWT. 2016; 74:135-144.

5. Altan, A, Maskan M. Development of extruded foods by utilizing food industry by-products. In: Advances in Food ExtrusionTechnology, 2016, 121-160. CRC Press, Boca Raton.

6. Athar N, Hardacre A, Taylor G, Clark S, Harding R. McLaughlin J., 2006. Vitamin retention in extruded food products. Journal of Food Composition and Analysis, 
19(4):379-383.

7. Baskar G, Aiswarya R. Role of extrusion technology in food processing and its effect on nutritional values. International Journal of Food science and Technology, 2016; 1:1-4

8. Bordoloi R, Ganguly S. Extrusion technique in food processing and a review on its various technological parameters. Indian Journal of Scientific Research and Technology. 2014; 2:1-3.

9. Camire ME. Chemical and nutritional changes in food during extrusion. In: Extruders in food applications, CRC Press, Boca Raton, United States of America, 2000, 127147.

10. Chen FL, Wei YM, Zhang B. Chemical cross-linking and molecular aggregation of soybean protein during extrusion cooking at low and high moisture content. LWT Food Science and Technology. 2011 44:957-962.

11. Devi BK, Kuriakose SP, Krishnan AVC, Choudhary P, Rawson A. Utilization of by-product from tomato processing industry for the development of new product. Journal of Food Processing and Technology, 2016; 7:608.

12. Emin MA, Schuchmann HP. A mechanistic approach to analyze extrusion processing of biopolymers by numerical, rheological, and optical methods. Trends in food Science \& Technology. 2017; 60:88-95.

13. Fellows P. Food processing technology: principles and practice (2nd ed.) CRC Press, Boca Raton, United States of America, 2000, 267-276.

14. Gurbuz YAVUZ. Heat Applications in Feed and Food Processing. International Journal of Advances in Science Engineering and Technology. 2017; 5(3-1):33-37.

15. Guy R. Extrusion Cooking Technologies and Application. Boca Raton Boston New York Washington, DC, 2001; 1-200.

16. Ilo S, Schoenlechner R, Berghofe E. Role of lipids in the extrusion cooking processes. Grasas y Aceites. 2000; 51:97-110.

17. Joshi VK, Kumar S. Meat Analogues: Plant based alternatives to meat products. International. Journal of Food Fermentation and Technology. 2015; 5(2):107-119,

18. Kendall CWC, Esfahani A, Jenkins DJA. The link between dietary fibre and human health. Food Hydrocolloids. 2010; 24:42-48.

19. Kothakota A, Jindal N, Thimmaiah B. A study on evaluation and characterization of extruded product by using various byproducts. African Journal of Food Science. 2013; 7:485-497.

20. Li R, Jia X, Wang Y, Li Y, Cheng Y. The effects of extrusion processing on rheological and physicochemical properties of sesbania gum. Food hydrocolloids. 2019; 90:35-40.

21. Maurya AK, Said PP. Extrusion Processing on Physical and Chemical Properties of Protein Rich Products. Journal of Bioresources Engneering and Technology. 2014; 2:61-67

22. Navale AS, Swami BS, Thakor JN. Extrusion cooking technology for foods. Journal of Ready to Eat Food, 2015; 2:66-80

23. Pansawat N, Jangehud K, Jangchud A, Wuttijumnong P, Saalia FK, Eitenmiller RR et al. Effects of extrusion conditions on secondary extrusion variables and physical properties of fish, rice-based snacks. LWT-Food Science and Technology. 2008; 41(4):632-641.

24. Pathak N, Kochhar A. Extrusion technology: Solution to
Develop Quality Snacks for Malnourished Generation. International Journal of Current Microbiology and Applied Sciences. 2018; 7(1):1293-1307

25. Petitot M, Abecassis J, Micarda V. Structuring of pasta components during processing: impact on starch and protein digestibility and allergenicity. Trends in Food Science and Technology. 2009; 20:521-532.

26. Rao RGH, Thejaswini LM. Extrusion Technology: A Novel Method of Food Processing. International Journal of Innovative Science, Engineering \& Technology. 2015; 2:358-369

27. Riaz MN. Introduction to extruders and their principles. In: Extruders in food applications, CRC Press, Boca Raton, United States of America, 2000, 1-23.

28. Sadler MJ. Meat alternatives- market developments and health benefits. Trends in Food Science and Technology, 2004; 15(5):250-260.

29. Sandey KK, Goel B, Karthikeyan S, Kumar A, Agrawal SU, Choudhary KK et al. Sensory characteristic of fresh extruded peda. Journal of Plant Development Sciences. 2018; 10:337-342.

30. Shilev S, Naydenov M, Vancheva V, Aladjadjiyan A. Composting of food and agricultural wastes. In: Utilization of Byproducts and Treatment of Wastes in the Food Industry, 2006, 283-302.

31. Singh S, Gamlath S, Wakeling L. Nutritional aspects of food extrusion: a review. International Journal of Food Science and Technology. 2007; 42:916-929.

32. Steel, C., Leoro, M., Schmiele, M., Ferreira, R., and Chang, Y. Thermoplastic extrusion in food processing. In: ThermoplasticElastomers, 2012, 265-284.

33. Tiwari U, Cummins E. Nutritional importance and effect of processing on tocols in cereals. Trends in Food Science and Technology, 2009; 20:511-520.

34. Varsha KR, Pavani S. Protein enriched ragi flakes. Research and Reviews: Journal of Food and Dairy Technology. 2016; 4:13-33.

35. Zielinski H, Michalska A, Piskula MK, Kozlowska H. Antioxidants in thermally treated buckwheat groats. Molecular Nutrition and Food Research, 2006; 50(9):824-832. 